\title{
NI SUMISAS NI SOMETIDAS. LA MUJER PARAGUAYA DESDE LAS FUENTES (1840-1860)
}

\section{PAGLIALUNGA, Viviana ${ }^{1}$ \\ https://orcid.org/0000-0002-8624-0050}

RESUMEN: Desde el punto de vista histórico y social, la imagen de la mujer abnegada y sumisa en Paraguay, vinculada con el término Kuña guapa, impide visualizar a la mujer paraguaya desde otra mirada. Por esta razón el objetivo de la presente investigación apuntó a elaborar una aproximación a la imagen de la mujer paraguaya desde una perspectiva histórico/jurídica; utilizando para el efecto el análisis del marco legal de la época y los casos de denuncias por divorcio realizadas por mujeres en el período 18401860. El tipo de investigación corresponde a la investigación histórica, mientras que el nivel del trabajo es descriptivo, con un diseño documental y bibliográfico. El análisis del marco jurídico vigente, junto a la bibliografía y a la documentación de archivo seleccionada y analizada nos lleva a una revisión histórica en clave femenina que rescata el protagonismo de las mujeres en el pasado desde sus historias de vida y al mismo tiempo brinda herramientas con las cuales repensar la historia de las mujeres paraguayas. El estudio del ámbito privado, alejado de cuestiones exclusivamente bélicas o económicas se constituye en un importante aporte en la construcción del conocimiento histórico y el papel de las mujeres en la sociedad paraguaya.

PALABRAS CLAVE: Paraguay; siglo XIX; mujer; divorcio.
ABSTRACT: From the historical and social point of view, the image of the selfsacrificing and submissive woman in Paraguay, linked to the term Kuña guapa, makes it impossible to see Paraguayan women from another perspective. For this reason, the objective of this research aimed to elaborate an approach to the image of Paraguayan women from a historical / legal perspective; Using for this purpose the analysis of the legal framework of the time and the cases of divorce complaints filed by women in the period 1847-1860. The type of research corresponds to historical research, while the level of work is descriptive, with a documentary and bibliographic design. The analysis of the current legal framework, together with the bibliography and the archival documentation selected and analyzed, leads us to a historical review in a female key that rescues the role of women in the past from their life stories and at the same time provides tools with which rethink the history of Paraguayan women. The study of the private sphere, away from exclusively military or economic issues, constitutes an important contribution in the construction of historical knowledge and the role of women in Paraguayan society.

KEYWORDS: Paraguay; 19th century; woman; divorce.

$1 \quad$ Magister en Educación, Licenciada en Educación y en Ciencias Sociales. Docente investigadora de la Universidad Nacional de Pilar desde el año 2013, y catedrática de historia en el colegio Goethe de Asunción. E-mail: mpaglialunga@hotmail.com 


\section{INTRODUCCIÓN}

Los trabajos de investigación histórica en torno a las historias de las mujeres han cobrado una notable importancia en las últimas décadas, como así también su visibilización, tanto a nivel internacional como en el Paraguay. El particular contexto histórico de nuestro país y las consecuencias sociales que acarreó el fin de la guerra contra la Triple Alianza (1865-1870) se proyectó en trabajos de investigación que se centraron en la imagen de la mujer durante el denominado período de la Reconstrucción (1870-1880). En su mayoría, estas investigaciones se enfocan en el rol de la mujer en esta reconstrucción como sostén no solo social, sino que también económico de un país en ruinas; tales son los casos de trabajos como los de Masare de Kostianovsky (2012) o Ribeiro Da Silva (2010).

También existen numerosos abordajes sobre las mujeres en la época de la conquista y colonización de la Cuenca del Río de la Plata en diversos trabajos a nivel regional, considerando que, ante todo, la historia del Paraguay se encuentra ligada a la del Río de la Plata, o viceversa, desde la llegada de los primeros españoles hasta los procesos de independencia. Muchos de estos trabajos versan sobre la imagen de Doña Mencía Calderón de Sanabria, apodada La Adelantada, quien fuera una de las primeras mujeres españolas en llegar a la región del Plata en tiempos de la conquista, y en menor medida, pero no menos importantes son los estudios sobre la mujer guaraní, siendo la mayoría de éstos bajo un enfoque más antropológico que histórico.

Por otro lado, los estudios sobre la mujer en la primera mitad del siglo XIX se centran en su mayoría a la descripción de la mujer de sociedad, sus usos y costumbres, su ropa y su rol de madre. Tal vez uno de los trabajos más logrados en lo que respecta a una historia de la mujer lo constituye la obra de Idalia Flores de Zarza, La mujer paraguaya protagonista de la historia (1537- 1879). Un antecedente importante lo constituye el trabajo de Ana Barreto en su trabajo denominado Voces de mujer en la historia paraguaya. De rigor es mencionar los valiosos aportes realizados por la Mary Monte de López Moreira en numerosos trabajos que abordan el tema de la mujer siendo el eje de historia social y género su enfoque actual de investigación: Al fin ciudadanas (2011) y Alquimistas. Documentos para otra historia de las mujeres (2013) ambos trabajos realizados con Clyde Soto y Line Bareiro.

Desde el punto de vista social y de la memoria histórica, la imagen de la mujer abnegada y sumisa, muchas veces vinculada con el término Kuña guapa, que todo lo aguanta es una imagen que impide visualizar a las mujeres paraguayas desde otra perspectiva. Por esta razón el objetivo de la presente investigación fue elaborar una aproximación a la imagen de las mujeres paraguayas desde una perspectiva histórico/jurídica; utilizando para el efecto 
el análisis del marco legal de la época y los casos de denuncias por divorcio realizadas por mujeres en el período 1847-1860.

\section{APROXIMACIÓN AL MARCO JURÍDICO VIGENTE ENTRE LOS AÑOS 1840 Y 1860 EN PARAGUAY}

Según la investigadora Bárbara Potthast (2011), al igual que otros estudiosos del derecho, las condiciones legales de la mujer en el siglo XIX, en especial durante la primera mitad de este siglo, no diferían de las demás legislaciones hispanoamericanas de la época y que, a su vez, todas estas tampoco diferían en gran medida de la legislación colonial.

Hablar de un marco Jurídico de la mujer en la época es simplemente referenciar aquellos apartados - aquellos pocos apartados - en los cuales la figura de la mujer es sujeto de derecho en la legislación de la época. Para el efecto se hace referencia para el marco temporal de la presente investigación las leyes de Paraguay de 1844 y las de 1842. En ambos casos, estos cuerpos legales distaban de ser un cuerpo jurídico completo. Las observaciones que señalan la complementariedad de estas nuevas leyes con las leyes españolas en vigencia corroboran dicha afirmación; todo esto sin menospreciar el valor del proceso de crecimiento legal que el Paraguay estaba experimentando desde la llegada de Don Carlos Antonio López al ejercicio del poder en Paraguay. Esta apreciación es sostenida por Potthast que señala cuanto sigue:

López se esforzó en acomodar paulatinamente su país a las normas europeas vigentes, no solo en lo material sino también en lo cultural y en lo administrativo (...) comenzó en primer lugar por ordenar el sistema de derecho y el policial. Derogo las Leyes coloniales de Indias por indignas de una República independiente y se apoyó nuevamente en la antigua legislación española de Toro y en las Leyes de Castilla, así como en las siete partidas de Alfonzo el Sabio. (POTTHAST, 2011, p.77)

Por lo señalado, es que se realiza un acercamiento a estos cuerpos legales partiendo del más cercano en el tiempo - considerando el marco temporal de la presente investigación - y en retrospectiva se realiza una breve descripción de aquellos documentos de legislación española todavía vigentes en la época que eran complementarios a las nuevas leyes nacionales.

Es importante destacar que en los casos judicializados sobre divorcio existía una intervención previa de la Iglesia católica, y que, inclusive, muchos de los pleitos no llegaron al ámbito judicial. En lo que respecta al derecho canónico de esta época es una línea de investigación nueva que se abre para dar luz a nuevas investigaciones. 
En 1844 se elabora un cuerpo legal denominado Ley que establece la administración política de la República del Paraguay, y demás que en ella se contiene, y en el Título X art. 11 de la misma se señala la ratificación de las leyes y decretos sancionados por el Soberano Congreso de 25 de noviembre de 1842 (PANGRAZIO, 1947, p.27). En esta ley se presentan 10 títulos bajos los cuales se organizan diversos artículos, siendo del I al IX relacionados a aspectos de los poderes del Estado y la organización de éstos, y el número $\mathrm{X}$ denominado Ordenanzas generales que habla sobre los ciudadanos, en líneas generales.

Artículo 1. Los ciudadanos de la República presentarán su reconocimiento y obediencia al presidente nacional luego de estar en posesión del mando, y en la forma que lo determine el presidente de la República.

Artículo 2. Los hombres son de tal manera iguales ante la ley, que esta, bien sea penal, preceptiva o tuitiva, debe ser una misma para todos, y favorecer igualmente al poderoso que al miserable.

Artículo 3. Todos los habitantes de la República tienen derecho a ser oídos en sus quejas por el Supremo Gobierno de la Nación.

(...)

Artículo 11. Se ratifican las leyes y decretos sancionados por el Soberano Congreso de 25 de noviembre de 1842. (PANGRAZIO, 1947, p.27)

En el abordaje que se realizó a los diversos documentos de época, se pudo comprobar, en especial en casos de demanda por divorcio, que la condición social de las mujeres, en algunos casos mencionadas como "pobres de toda solemnidad" (ANA- SH-295n34-188-189) no les impidió contar con el amparo de la ley, cumpliendo de esta manera con los principios de la Ley de Administración de la República del Paraguay, Título X artículos 2 y 3 sobre de igualdad ante la ley y el derecho a ser oídos en sus quejas por el Supremo Gobierno de la Nación.

Considerando que se ratifican las leyes y decretos sancionados por el Congreso de 1842 continuamos en forma regresiva analizando los aspectos legales.

En 1842 se promulgó el Estatuto Provisorio de la Administración de Justicia en el cual se confirmaba la independencia judicial en el Paraguay con la creación de Tribunales Superiores emancipados del Ejecutivo, mientras que el gobierno ejercía el poder judicial en causas de traición a la patria o conjuración contra el orden público. Se creó el departamento de policía encargada de la atención del orden social y la prevención y represión de los delitos. Se abolió la pena de muerte y la confiscación de bienes (MONTE DE LÓPEZ MOREIRA, 2017 , p.171). En este cuerpo legal, se derogan las leyes de Indias (art. 72) y se sostienen las leyes de Castilla, la de las partidas y las de Toro (art. 73) mientras la república no sancione sus códigos (MONTE DE LÓPEZ MOREIRA, 2017, p.171). 
Anterior a la promulgación del Estatuto provisorio, el gobierno consular estableció también decretos oficiales, señalados por Bárbara Potthast de la siguiente manera:

Carlos Antonio López promulgo el 27 de junio de 1842 otro decreto reglamentando los asuntos públicos (...) disponía que los jueces de paz, asistidos por otros representantes estatales como los oficiales y celadores, debían vigilar la moral y las buenas costumbres (...) debían ejercer presión sobre todos los amancebados públicos para que estos cambien su escandalosa vida y sobre todo los esposos separados, para que éstos se unan nuevamente. (POTTHAST, 2011, p.78)

Señala Potthast la existencia de diversos documentos de la sección judicial del A.N.A. Archivo Nacional de Asunción en los cuales son numerosas las protestas en el interior del país, o también conocido como "pueblos de la campaña" por perseguir el amancebamiento, que estaba muy arraigado en todo el territorio. Por otro lado, señala también el hecho de que las disputas personales entre los pobladores y los celadores o cabos podían provocar denuncias de este tipo. A pesar de esto, los Jueces cumplían con su misión, y en líneas generales, las mujeres amancebadas eran dadas en guarda a familias respetables y los hombres eran normalmente amonestados. Ejemplos de este caso se analizan en el siguiente apartado.

(...) este decreto de C. A. López constituyó una medida a favor de las mujeres. Sin embargo, esto exigiría el supuesto de que un matrimonio era siempre beneficioso para la mujer paraguaya, una tesis por lo menos dudosa desde la perspectiva actual. La convivencia forzosa de esposos, algunos de los cuales vivían separados desde hacía varios años, a veces era problemático para las mujeres, como lo prueban algunos casos (POTTHAST, 2011, p.85).

En forma complementaria, las leyes de Castilla, de Toros y de las Siete partidas seguían vigentes en forma complementaria durante el período abordado en la presente investigación. La denominada Novísima recopilación de las leyes de España o también conocida como Leyes de Castilla se encuentra dividida en XII libros. En que se reforma la Recopilación publicada por el Señor Don Felipe II en el año de 1567 y reimpresa en 1775. Y se incorporan las pragmáticas, cédulas, decretos, órdenes y resoluciones reales, y otras providencias no recopiladas, y expedidas hasta el de 1804. Mandada formar por el señor don Carlos IV, la impresión se realiza en Madrid en 1805, en la Imprenta de Sancha. Apartados específicos que contemplen la figura de la mujer desde el aspecto legal en Las leyes de Castilla aparecen siempre en relación con el matrimonio, y se los encuentra en el libro X; y en algunos casos en el libro XI que trata sobre diversos delitos, como el caso del amancebamiento. 


\section{LEYES DE CASTILLA. TÍTULO XXVI \\ De los amancebados y mujeres públicas}

1- Pena del casado que tuviere manceba pública.

2- Pena del que tenga por manceba pública a una mujer casado; y del casado que viviere en casa de la manceba, dejando la de su mujer

3- Pena de las mancebas de clérigos, frailes y casados; y modo de librar los pleitos de ellas en la Corte

4- Modo de proceder las justicias contra las mancebas de los clérigos, y contra los maridos de ellas que las consientan.

5- Amonestación y castigo de las mujeres casadas y sospechosas que estuvieren en las casas de los clérigos

6- Prohibición de tener las mujeres públicas criadas menores de cuarenta años y escuderos; y de usar hábito religioso, almohada y tapete en las Iglesias

7- Prohibición de mancebías y casas públicas de mujeres en todos los pueblos de estos reinos.

8- Recogimiento de mujeres perdidas de la corte y su reclusión en la galera.

En el caso de las Leyes de Toro, se repite el mismo caso, donde la mujer es mencionada siempre en relación con el matrimonio o adulterio. Los números 14, 15 y 16 se mencionan aspectos del "matrimonio suelto", es decir, que se puede interpretar como divorcio considerando que también menciona la posibilidad de nuevo matrimonio. La ley 80 señala que la denuncia de adulterio por parte del esposo debe incluir a los dos adúlteros, no solo a uno de ellos. Leyes 81 y 82 estipula los casos de adulterio, con la salvedad de que en este punto cuenta el adulterio de la mujer, pero no así el adulterio del hombre. Inclusive señala el hecho que, aunque la mujer llegase a demostrar que el matrimonio era nulo por algunas de las múltiples dispensas en relación con el mismo, el hombre igual podría denunciar el adulterio. Por otro lado, en la siguiente ley se establece que si el esposo mata a la esposa no se quedará con su dote.

\section{LEYES DE TORO}

81. Si alguna mujer, estando con alguno casada, o desposada por palabras del presente en faz de la santa madre Iglesia, cometiere adulterio, que aunque se diga y pruebe por algunas causas o razones que el matrimonio fue ninguno, ora por ser parientes en consanguinidad o afinidad dentro del cuarto grado, ora porque cualquiera de ellos sea obligado antes a otro matrimonio o haya hecho voto de castidad o de entrar en religión, o por otra cosa alguna, pues y a por ellos no quedó de hacer lo que no debían, que por esto no se escuses a que el marido pueda acusar de adulterio como si el matrimonio fuese verdadero, y mandamos que en estos tales, que así vemos por adulterio, y en sus bienes, se ejecute lo contenido en la ley del fuero de las leyes, que habla cerca de los que comenten delito de adulterio.

82. El marido que matare por su propia autoridad al adultero y a la adultera, aunque los 
tome infraganti delito, y sea justamente hecha la muerte, no gane la dote ni los bienes del que matare, salvo si los matare, o condenare por autoridad de nuestra justicia, que en tal caso mandamos que se guarde la ley de fuero de las leyes que este caso dispone.

El origen de Las Leyes de las Siete Partidas las ubicamos en el siglo XIII y en la Corona de Castilla, de gran significación para la legislación española e hispanoamericana. En ellas se fijaron las normas sobre el divorcio, manteniendo el término lingüístico utilizado desde el derecho romano, aunque aplicado a una determinada forma de separación conyugal (ESPÍN LÓPEZ. 2016, p.169). En la cuarta partida, ley 2, título 10 se especifica que el divorcio podía darse por dos razones fundamentales, una de índole religioso y otra por adulterio; en ambos casos debía ser sentenciada en juicio.

\section{LEYES DE LAS SIETE PARTIDAS}

Cuarta Partida, Título 10; Ley 2: Propiamente hay dos razones y dos maneras de departimiento a las que pertenece este nombre de divorcio, comoquiera que sean muchas las razones por las que separen a aquellos que semeja que están casados y no lo están por algún embargo que hay entre ellos; y de estas dos es la una religión, y la otra, pecado de fornicación. Y por la religión se hace divorcio en esta manera, pues si algunos que son casados con derecho, no habiendo entre ellos ninguno de los impedimentos por los que se debe el matrimonio separar, si a alguno de ellos, después que fuesen juntados carnalmente, les viniese en voluntad entrar en orden y se lo otorgase el otro, prometiendo el que queda en el mundo guardar castidad, siendo tan viejo que no puedan sospechar contra él que hará pecado de fornicación, y entrando el otro en la orden, de esta manera se hace del departimiento para ser llamado propiamente divorcio, pero debe ser hecho por mandato del obispo o de alguno de los otros prelados de la iglesia que tienen poder de mandarlo. Otrosí haciendo la mujer contra su marido pecado de fornicación o de adulterio, es la otra razón que dijimos por que hace propiamente el divorcio, siendo hecha la acusación delante del juez de la iglesia, y probando la fornicación o el adulterio. Esto mismo sería del que hiciese fornicación espiritualmente tornándose hereje o moro o judío, si no quisiese hacer enmienda de su maldad.

El análisis realizado en el marco legal que corresponde al Paraguay en el período estudiado nos presenta dos realidades. Por un lado, una incipiente organización jurídica en un país que daba sus primeros pasos apuntando a una modernización en múltiples aspectos, entre ellos, la justicia y la ciudadanía (en el contexto temporal que le corresponde). Por otro lado, los pocos apartados que mencionan específicamente la figura de la mujer son con relación a la dote, el matrimonio, el adulterio y el divorcio. En este análisis es importante destacar nuevamente que, al no ser un cuerpo legal completo, se complementó con leyes anteriores que continuaron en vigencia en la época. 


\section{LA KUÑA GUPA, UN IMAGINARIO QUE DESDIBUJA LA IMAGEN}

La representación generalizada en el imaginario popular sobre la mujer paraguaya tiene relación directa a profundos procesos históricos que cambiaron en forma radical a la sociedad. Las devastadoras consecuencias demográficas de la guerra contra la Triple Alianza (1865-1870) configuraron una sociedad mayoritariamente femenina, que cargó forzosamente con la dura labor de la reconstrucción en todos los sentidos, pero por sobre todas las cosas la reconstrucción económica y social. Los apuntes que realiza Clyde Soto con respecto a esta formación del imaginario sobre esta mujer giran en torno a la interpretación del término popular de Kuña guapa alejando dicho término de la imagen de una mujer empoderada en su rol para interpretarlo como una verdadera marca cultural del sufrimiento y la resignación de la mujer paraguaya, que en realidad la posicionan desde la subordinación (SOTO, 2009:5). En su interpretación, reconoce sin dudas el heroísmo y sacrificio de estas mujeres, pero que al mismo tiempo "fueron eternizadas en el rol secundario de entusiastas y sumisas acompañantes de los guerreros, y en el de trabajadoras incansables ante la desgracia nacional" (SOTO, 2009, p.6). Al decir de la autora, el término Kuña guapa quedó asociado a un ideal de mujer que da responsabilidades, pero no da derechos.

Pero estas mujeres reconstructoras, son el reflejo de aquellas que las antecedieron, y actuaron en consecuencia a un modelo que lejos de ser sumisas y sometidas, supieron enfrentar situaciones personales difíciles, e hicieron uso de los recursos legales con los que contaban. El paso de una imagen de sumisión al de una imagen de mayor empoderamiento radica en visibilizar estas otras aristas de la vida de las mujeres paraguayas.

\section{ANÁLISIS DE FUENTES DOCUMENTALES. UNA APROXIMACIÓN A HISTORIAS DE VIDA DE MUJERES PARAGUAYAS.}

Sobre lo que se ha escrito, pero tiene todavía escasa difusión es acerca de la lucha y resistencia por parte de las mujeres, aquellas que a pesar del tiempo histórico que les tocó vivir, enfrentaron sus circunstancias particulares e iniciaron procesos de demandas por maltrato y juicios por divorcio. Incluso juicios y petitorios sobre aspectos que estaban reglados en la ley y a pesar de las circunstancias particulares de la sociedad de la época las mujeres lo supieron enfrentar. Ana Barreto en su trabajo denominado Voces de mujer en la historia paraguaya presenta algunos ejemplos significativos al respecto y cita casos como el de Gregoria Micaela Centurión, una viuda que en 1816 se opone a perder la patria potestad del hijo menor por contraer un nuevo matrimonio. Otro caso mencionado por la autora es el de pedido de divorcio presentado por María Manuela Aponte en 1823, citado también por 
Potthast (2011) y Barreto Valinotti, (2012).

Mi marido es un cruel, señor Provisor, y para probar esta su aborrecida condición provoqué y provoco el juicio ordinario, así como para librarme de su venganza próxima (...) Por otro lado también es falso y aun ridículo suponer que la mujer sea pies del matrimonio sólo porque el marido sea su cabeza, porque aquella no es sino compañera, y este administrador de sus bienes. De la costilla de Adán se sabe, se formó un Consorte, y no de la parte inferior ínfima del cuerpo. Y si se dice que debe estar sujeta al marido, es únicamente en aquello que convenga a la felicidad espiritual y temporal de ambos, porque tampoco ella es esclava sino muy ingenua e igual en todo con su esposo, pues de lo contrario sería sierva sino compañera: lo cual es falso. (ANA. SH.226n23-270-276)

Al respecto es importante aclarar que, los casos mencionados anteriormente se encuentran ubicados dentro del marco temporal que corresponde al gobierno del Dr. Francia; y que durante el mismo la competencia de la iglesia había disminuido notablemente con relación al poder civil y, posteriormente, con la restitución de los vínculos con la curia en épocas de Carlos Antonio López la Iglesia como institución vuelve a velar por las cuestiones de los matrimonios. Será recién en 1843 y 1844 cuando se difundieron normas generales para la administración de los asuntos de jurisdicción eclesiástica y reglas sobre cuestiones de matrimonio (POTTHAST, 2018, s/p). Por esta razón es que, los documentos abordados para el análisis de las historias de vida corresponden ya al ámbito jurídico y no al eclesiástico.

En la sección civil y judicial del A.N.A -Archivo Nacional de Asunción- figuran numerosos documentos relativos a divorcios, sobre los cuales Bárbara Potthast ha realizado un profundo análisis estadístico (POTTHAST, 2011, s/p) algunos de ellos fueron seleccionados para este trabajo y se ha realizado su transcripción. De las trascripciones se extrajeron aquellos argumentos que evidencian la existencia de mujeres valientes, que frente a un sistema que prácticamente no las cuenta como sujeto de derecho se enfrentar a sus problemas desde lo legal.

\section{Caso 1. 1844. Demanda de Francisca Dolores Sánchez, contra su marido Francisco Ignacio Núñez}

Dolores Sánchez, casada ocho años con Francisco Núñez, presenta el siguiente argumento en la demanda que entabla contra su esposo:

(...) lexos de propender al inviolable cumplimiento de los deberes que el sacramento del matrimonio nos impone, ha procedido audazmente infringiéndolos, y mirándolos con una omisión culpable y punible indiferencia, dándome suficientes motivos y causales para un justo divorcio. (ANA SCJ Vol. $2198 \mathrm{~N}^{\circ} 2$ ) 
Y a continuación cita los numerosos motivos que la animaron a presentar la demanda: intolerable crueldad y frecuentes maltratos y castigos provocados por sus borracheras diarias; un golpe con vara en ojo motivado por llegar a la casa luego de 15 días de ausencia y no encontrar que comer; llevarse la ropa de la mujer dejándola desnuda en la casa para que no pueda salir; cortar de raíz su pelo acusándola falsamente; además de los castigos físicos a la mujer también cometía maltratos físicos contra sus padres.

(...) por todo lo cual no me queda más arbitrio en circunstancia tan deplorable en que me hallo que instaurar demanda de divorcio contra mi expresado marido, como desde luego lo verifico, con protesta de ampliarla cuando a mi derecho convenga y de justificarla legalmente, suplicando a Vuestra Superioridad se sirva habida por verídica, declarar divorcio entre nosotros (ANA SCJ Vol. $2198 \mathrm{~N}^{\circ} 2$ ).

Esta causa que había sido iniciada el 9 de julio de 1843 y presentada a las autoridades el 12 del mismo mes, no tenía respuesta cuatro meses después de iniciada, evidenciada con una nota fechada el 06 de octubre de dicho año, con un reclamo realizado por el representante de la demandante. El 12 de noviembre el cura de la Recoleta notifica ante testigos de la demanda de divorcio a Francisco Ignacio Núñez, que manifestó entender y acatar la orden de la vicaría. Sin embargo, las siguientes notas ponen de manifiesto la rebeldía del cónyuge con nota del 24 de noviembre. Pero esto no termina aquí, puesto que otro documento dirigido al Sr. Vicario General dice textualmente "un año y tres meses poco más o menos há que entable demanda de divorcio en el juzgado eclesiástico (...) suplico se sirva mandar, se lleve a debido efecto este último decreto (...)" (ANA SCJ Vol $2198 \mathrm{~N}^{\circ} 2$ ) es en noviembre de 1843 cuando se realizan los interrogatorios a los testigos.

Increíblemente, a mediados del mes de diciembre de 1843, el demandado presenta un recurso argumentando que la no presentación de libelos de su parte fue por su estado de insolvencia, que no tiene impugnaciones a los alegatos de su consorte y solicita lo siguiente:

(...) de consiguiente convengo desde luego en el divorcio solicitado por mi enunciada consorte con tal de que sea temporal. Y para ello V.S. pido y suplico (...) se sirva proceder a nuestro enunciado divorcio, protestando y desde luego a ratificarme en mi indicado convenio, o conformidad por ser de justicia que pido pasando por Dios que no procedo de malicia con lo demás necesario en Dios (ANA SCJ Vol. 2198 № 2).

Corría ya enero de 1844 cuando Francisca Dolores solicita al vicario se sirva sentenciar la expresada causa, declarándose entre ambos cónyuges divorcio temporal quoad thorum et cohabitationem. ${ }^{1}$ ¿Cómo y cuándo termina esta historia? Concluye el 27 de

1 Se distinguen dos tipos de divorcio en la época: el menos pleno o imperfecto (divortium 
enero de 1844, otorgando el divorcio a favor de Francisca Dolores y condenando a Francisco Ignacio cargándole los costos y costas del proceso.

\section{Caso 2. 1847. Proceso a Fernando Arza por vida ilícita.}

María de la Paz Barreto era una mujer de Villa del Pilar casada con José Sacarías Díaz, quienes se habían separado voluntariamente. Ella mantenía una relación con un indio según reza el documento llamado Fernando Arza. Como para la época ya estaba en vigencia el decreto de Don Carlos de intentar unir a las parejas que estaban legalmente casadas y separadas, y era costumbre denunciar las relaciones ilícitas a los comandantes de las villas y compañías, y que los comandantes actuaran en estos casos, la autoridad local redacta de la siguiente manera el documento elevado a las autoridades:

Habiendo sido informado en esta vecindad la ilícita y escandalosa relación que tiene María de la Paz Barreto, esposa de, con un indio llamado Fernando Arza há sobre cinco años siendo todos vecinos de esta Villa y que estos casados ya desde mucho tiempo vivían separados voluntariamente ambos en compañía de sus madres, en esta virtud há efecto de propender al remedio de tan escándalos vida hice comparecer ante mí al expresado indio ordenándole directamente que deje de llegar ya a la casa de María de la Paz Barreto (...) y también a há Sinforosa Barreto, madre de la expresada (...) para que en lo sucesivo por pretexto alguno permita llegar en su casa a Fernando Arza (...) he sabido que siempre frecuentaba la casa el indio quebrantando mi orden (...) por cuya razón hice comparecer ante mí a ambos consortes, amonestándoles por dos veces que volvieron a juntarse por vía de conciliación, previniendo a la mujer que si esta medida no fuera bastante para reportarse y seguir otra vez la compañía de su marido me hallaría preciado a dar parte a V.E. de su incorregibilidad (A.N.A. SCJ Vol. 1515 N¹0).

Ante esta situación, la mujer alega que no será posible volver con su marido, porque su marido, injustamente, le había mandado azotar en una escalera y mandar poner grillos en el calabozo en tiempo de los otros alcaldes, y que estaba resuelta a solicitar el divorcio, y ante esto se solicita consideración, a lo que se suma el hecho de que no tenían hijos.

La respuesta del presidente López está fechada un 7 de abril de 1847, es que el alcalde ordinario se informe sobre las quejas de María Barreto contra su marido y que al indio Francisco Arza se lo remita por agua a la Capital al cuartel de Lanceros.

El alcalde en respuesta al pedido del presidente remite otra nota fechada el 13 de abril de 1847 en el que expresa que ha recibido a tres testigos, por cierto, todos hombres,

quoad thorum et cohabitationem), que se limita a suspender la vida común; y el pleno o vincular (divortium quoad vinculum), que produce la ruptura del vínculo y reconoce la libertad a las partes para contraer nuevas nupcias con tercera persona. https://mercaba.org/Rialp/D/divorcio.htm 
para recibir informes sobre esta pareja. El primer testigo ratifica las denuncias y también los castigos que recibió María de la Paz; el segundo testigo agrega a las declaraciones que la separación del María de la Paz era resultado de los continuos quebrantos, y que luego de la separación tuvo relación ilícita con tres sujetos, y que el último, Fernando Arza tenía siempre con ella tratos libres sospechosos y que "a él mismo le consta" por ser vecino de la expresada María de la Paz. El tercer testigo argumenta la misma versión del primero. Pero ahora le tocaba el turno a María de la Paz, para poder dar su versión. En el documento expresa que luego de casada con su marido tuvo un año de matrimonio pacífico, hasta que ella se enteró de una relación ilícita del marido con una mujer casada, "le había hecho cargo" y que esto inició los maltratos por parte del marido, verbales y físicos, con látigo e inclusive cuchillo, con el que intentó matarla y no lo logró gracias a la oportuna aparición de un vecino en la casa. El marido pone quejas ante el alcalde de turno y es metida en el calabozo dos veces, la segunda con grillos; y otras dos veces bajo otro alcalde en los mismos términos de la primera vez, depositada en una casa de la villa y castigada con azotes en una escalera. Ante la pregunta sobre lo que originó dichos castigos María de la Paz, mencionó que el marido había enfermado de "aire perlático"2 (A.N.A. SCJ Vol. 1515 N$^{\circ} 10$ ) y que ella siempre salía a buscarle medicamentos y que sus demoras eran la causa de los castigos.

Este conjunto documental termina así, no habiendo otras notas que den continuidad al caso. Sin embargo, queda claro que las medidas tomadas por el Gobierno, aparentemente a favor de las mujeres para que los esposos vuelvan a unirse, no daban los resultados esperados. Fernando Arza, finalmente en el mes de abril se le destino a excavaciones y en el mes de Julio fue remitido a la capital (A.N.A. SCJ Vol. $\left.1515 \mathrm{~N}^{\circ} 10\right)$.

\section{Caso 3. 1854. Lorenza Ayala sobre divorcio.}

El siguiente caso, nuevamente por órdenes del Estado se obliga a reconciliarse a una pareja (Lorenza Ayala y Manuel Rosa Ayala) que se hallaba separada hacía más de 19 años, el marido, quien tenía una vida licenciosa y la había dejado abandonada a su suerte con dos hijas, retorna y utilizando los recursos económicos de su esposa pone en pie una carnicería, y luego trae a su concubina de San Estanislao y los hijos que con ella había tenido. La mujer indignada lo acusa ante el Juez de paz provocando la reacción del marido, que la corre por la calle, la alcanza, casi la ahorca y jura matarla haciendo una cruz con los

2 perlático. (persona) paralítico, impedido, tullido, imposibilitado. Es forma poco usual en la lengua con la que se hace referencia a la persona que padece perlesía o parálisis de algunas partes del cuerpo. es.thefreedictionary.com 
dedos en la boca a modo de promesa.

Como era de esperar, la mujer se negó a una nueva reconciliación presentando el pedido de divorcio. Es interesante la lectura del documento, en especial la afirmación de la tenaz resistencia de la mujer a convivir con su marido (ANA SCJ Vol. $1340 \mathrm{~N}^{\circ} 9$ foja 15) al que se sumaron descripciones de hechos de violencia contra su persona. Presentado el caso ya al Juez de primera instancia, nuevamente se verifica la defensa de los pobres puesto que la demandante está declarada como pobre de toda solemnidad y en notas se ratifica que el ministerio general de pobres se encargará de su defensa. En el extenso expediente que consta de más de 60 páginas inicia con el pedido de divorcio por la defensa en agosto de 1854. En seguidas notas el marido se declara insolvente y que no puede llevar las costas del caso.

El alegato de la defensa del cónyuge está elaborado en varias fojas donde desmiente todas y cada una de las acusaciones, para finalizar accede a la separación perpetua de su mujer. Los largos y protocolares testimonios jugaron a favor de Lorenza. Al igual que en otros casos, el defensor de Lorenza remite una nota al Juez de primera instancia en la cual menciona el vencimiento de los plazos legales de publicación de probanzas, en enero de 1855.

La sentencia a favor de Lorenza finalmente se da el 15 de marzo de 1855.

\section{CONCLUSIONES}

Realizar un acercamiento a una imagen histórica de las mujeres, diferente a la instalada en el imaginario es un arduo trabajo que recién inicia. Los nuevos trabajos realizados sobre las mujeres paraguayas del siglo XIX van construyendo lentamente una imagen que se edifica desde una visibilización de las mujeres más allá de su rol de madre de familia. El marco legal vigente en la segunda mitad del siglo XIX no difería en general del marco jurídico heredado de la España de la edad moderna, ni de la realidad social de la mujer durante la época de la colonia. El análisis de documentos realizados en el presente trabajo no difiere tampoco (en muchos aspectos) a las problemáticas actuales de las mujeres. A pesar de las notorias diferencias en lo que respecta a la adquisición de derechos para la mujer y los cambios jurídicos que fueron evolucionando, sobre todo durante el siglo $\mathrm{XX}$, la lectura de los documentos nos demuestra dos cosas: en primer lugar, que la problemática femenina no difiere mucho entre el pasado y el presente; y en segundo lugar y tal vez por el objetivo del presente trabajo la más importante, la oportunidad de visibilizar a mujeres que teniendo todo en contra decidieron enfrentar largos pleitos por divorcio. Los 
documentos analizados tuvieron resultados positivos para ellas, enfrentando no solo a la moral eclesiástica impuesta, sino a las leyes que poco las amparaban.

Una postura diferente a la imagen de sumisión y resignación heredada. Una imagen de una mujer empoderada, que como en el caso de Lorenza, completó 46 fojas de testigos a su favor, para lograr luego de más de 20 años de abandono de su esposo el anhelado divorcio; o como el caso de María de la Paz Barreto, que luego de su sometimiento físico y separación voluntaria tuvo que enfrentar una demanda de vida ilícita, o el caso de Francisca Dolores Sánchez, quien a pesar de sus múltiples argumentos y testigos tuvo que esperar más de dos años para su sentencia de divorcio definitiva. Estas no son mujeres sumisas ni sometidas, son mujeres autoconstruidas desde una sociedad que tenía sus propios códigos de convivencia, son mujeres que sentarán las bases de una sociedad que luego de la guerra, brindará verdaderas luchadoras silenciadas por el tiempo y escondida en los papeles a la espera ser halladas.

Los esfuerzos de Carlos Antonio López en la construcción de un marco jurídico regulador, y los decretos que apuntaban a regularizar la situación de los matrimonios separados, fue una clara muestra de que esas separaciones estaban ampliamente justificadas, y que, en muchos casos prevalecieron en los juicios de divorcio.

Adentrarnos en las problemáticas de las mujeres con la lectura de los documentos legales de la sección civil y judicial del Archivo Nacional de Asunción, colabora en la reconstrucción de un nuevo imaginario, que da un paso al costado de la mujer estereotipada sufrida y resignada, y nos acerca a una mujer paraguaya capaz de enfrentarse al sistema, con acciones reveladoras que se encuentran todavía ocultas en los documentos de archivo.

Mucho hay todavía por indagar, esta historia silenciada y poco conocida apunta a un acercamiento más real, desde las fuentes, desde los documentos de archivo, desde las voces de las mismas mujeres plasmadas en sus alegatos.

\section{BIBLIOGRAFÍA}

BARRETO VALINOTTI, Ana. Voces de mujer en la historia paraguaya. Asunción: Impresión Gráfica AGR, 2012

BERMEJO, Idelfonzo. Repúblicas americanas. Episodios de la vida privada, política y social en la República del Paraguay. Madrid: Imprenta de L. Labrajos, 1873

ESPÍN LÓPEZ, Rosa M. Los pleitos de divorcio en castilla durante la edad moderna. Estudios históricos. Historia Moderna, Universidad de Salamanca. Volumen 38 n 2, p 167200, diciembre de 2016. Obtenido de: https://revistas.usal.es/index.php/Studia Historica/ article/view/shhmo2016382167200/15937 
MASARE DE KOSTIANOVSKY, Olinda. La mujer paraguaya. Su participación en la Guerra Grande. Asunción: Fundación Latourrete Bo, 2012

MONTE DE LÓPEZ MOREIRA, Mary. Historia del Paraguay. Asunción: Servilibro, 2017.

MUÑOZ GARCÍA, María José. La condición jurídica de la mujer casada en Indias. Anuario de la facultad de derecho. Universidad de Extremadura, 1991, p. 455-474.

PANGRAZIO, Miguel Ángel. Constitución de la República del Paraguay y sus antecedentes. Asunción: Emasa,1947

POTTHAST, Bárbara. ¿Paraíso de Mahoma o país de las mujeres? El rol de la familia en la sociedad paraguaya del siglo XIX. Asunción: Fausto, 2011

POTTHAST, Bárbara. Amancebamiento y matrimonio en el Paraguay (siglo XIX). Versión digital. (https://books.openedition.org/, Ed.) Institut francaise détudes andines, 335-376. 2018

RIBEIRO DA SILVA, Alberto Moby.La noche de las Kygua Vera. La mujer y la reconstrucción de la identidad nacional en la posguerra de la Triple alianza. Asunción: Intercontinental, 2010

ROMANO, Martín. Sexo, amor y matrimonio en el Paraguay del siglo XIX. Academia.edu. (s/f) Obtenido de: https://www.academia.edu/34947803/Sexo_amor_y_matrimonio_en_el_ Parag uay_del_S._XIX.pdf?auto=download

SOTO, Clyde.Marcas culturales para las mujeres en la sociedad paraguaya. Primer foro Internacional del Bicentenario (págs. 1-8). 2009.Asunción: Centro de Documentación y Estudios. Obtenido de: http://www.cde.org.py/wp-content/uploads/2017/02/2009-ClydeSoto-Marcas-culturales.pdf

URBIETAROJAS, Pastor. La mujer paraguaya. Esquema historiográfico. Asunción: Colección Paraguay, 1962.

\section{FUENTES}

1844. Demanda de Francisca Dolores Sánchez, contra su marido Francisco Ignacio Núñez presentada al Vicario General y Juez Eclesiástico. ANA SCJ Vol. 2198 N$^{\circ} 2$

1847. Proceso a Fernando Arza por vida ilícita. ANA SCJ Vol. $1515 \mathrm{~N}^{\circ} 10$

1850. Designación de un defensor particular para la insolvente Rafaela Oliva, en una causa por divorcio. ANA SH Vol.295 N³4-188-189

1854. Lorenza Ayala sobre divorcio. ANA SCJ Vol. $1340 \mathrm{~N}^{\circ} 9$

\section{LEYES}

LEY QUE ESTABLECE LA ADMINISTRACIÓN POLÍTICA DE LA REPÚBLICA DEL PARAGUAY, Y DEMÁS QUE EN ELLASE CONTIENE. 1844. En: PANGRAZIO, Miguel Ángel. Constitución de la República del Paraguay y sus antecedentes. Asunción: Emasa,1947.

LEYES DE CASTILA

Gobierno de España. Boletín Oficial del Estado. Novísima recopilación de las leyes de España sancionada por Carlos IV en 1805. Tomo VI. Biblioteca Jurídica Digital. 1993. versión facsimilar disponible en: https://www.boe.es/biblioteca_juridica/publicacion. php?id=PUB-LH-1993-63\&tipo=L\&modo=2. 


\section{LEYES DE LAS SIETE PARTIDAS.}

Real Academia Española. Banco de Datos CORDE. Disponible en: https://www.docsity.com/ es/las-siete-partidas-alfonso-sabio/4949481/.

LEYES DE TORO

Estudio preliminar y transcripción de $\mathrm{M}^{\mathrm{a}}$ Soledad Arribas; presentación de Ramón Falcón Rodríguez. Madrid: Servicio de Publicaciones del Ministerio de Educación y Ciencia. 1977 https://faculty.georgetown.edu/sallesrv/courses/SPAN-459/span459/pdfs/leyes_toro/ leyes_96.pdf.

LEYES Y DECRETOS SANCIONADOS POR EL SOBERANO CONGRESO DE 25 DE NOVIEMBRE DE 1842. En: PANGRAZIO, Miguel Ángel. Constitución de la República del Paraguay y sus antecedentes. Asunción: Emasa,1947.

Recebido em 11/10/2021

Aprovado em 01/12/2021 